\title{
Optimization of ventilator setting by flow and pressure waveforms analysis during noninvasive ventilation for acute exacerbations of COPD: a multicentric randomized controlled trial
}

\author{
Fabiano Di Marco ${ }^{1 *}$, Stefano Centanni ${ }^{1}$, Andrea Bellone ${ }^{2}$, Grazia Messinesi ${ }^{3}$, Alberto Pesci ${ }^{3}$, Raffaele Scala ${ }^{4}$, \\ Andreas Perren ${ }^{5}$ and Stefano Nava ${ }^{6}$
}

\begin{abstract}
Introduction: The analysis of flow and pressure waveforms generated by ventilators can be useful in the optimization of patient-ventilator interactions, notably in chronic obstructive pulmonary disease (COPD) patients. To date, however, a real clinical benefit of this approach has not been proven.

Methods: The aim of the present randomized, multi-centric, controlled study was to compare optimized ventilation, driven by the analysis of flow and pressure waveforms, to standard ventilation (same physician, same initial ventilator setting, same time spent at the bedside while the ventilator screen was obscured with numerical data always available). The primary aim was the rate of $\mathrm{pH}$ normalization at two hours, while secondary aims were changes in $\mathrm{PaCO}_{2}$, respiratory rate and the patient's tolerance to ventilation (all parameters evaluated at baseline, 30, 120, 360 minutes and 24 hours after the beginning of ventilation). Seventy patients (35 for each group) with acute exacerbation of COPD were enrolled.
\end{abstract}

Results: Optimized ventilation led to a more rapid normalization of $\mathrm{pH}$ at two hours (51 vs. $26 \%$ of patients), to a significant improvement of the patient's tolerance to ventilation at two hours, and to a higher decrease of $\mathrm{PaCO}_{2}$ at two and six hours. Optimized ventilation induced physicians to use higher levels of external positive endexpiratory pressure, more sensitive inspiratory triggers and a faster speed of pressurization.

Conclusions: The analysis of the waveforms generated by ventilators has a significant positive effect on physiological and patient-centered outcomes during acute exacerbation of COPD. The acquisition of specific skills in this field should be encouraged.

Trial registration: ClinicalTrials.gov NCT01291303.

Keywords: chronic obstructive pulmonary disease, acute exacerbation, non invasive ventilation, ventilators

\section{Introduction}

Noninvasive positive pressure ventilation (NIV) is to date the first-line intervention for patients suffering from acute exacerbation of chronic obstructive pulmonary disease (COPD) and respiratory acidosis, reducing intubation rate and mortality [1-3]. The failure rate of NIV (that is, the need for endotracheal intubation or

\footnotetext{
* Correspondence: fabiano.dimarco@unimi.it

'Pneumologia Ospedale San Paolo, Università degli Studi di Milano, via A. di Rudinì 8, Milano, 20142, Italy

Full list of author information is available at the end of the article
}

death) for this collective is up to $25 \%$ [1,4-6], a percentage varying significantly according to the timing of NIV application and the fast response to this treatment [5]. During the most commonly used mode of NIV-Pressure Support Ventilation (PSV)-the "independent" variables to be set by the operator (that is, external positive endexpiratory pressure, PEEPext, level of support, speed of pressurization, sensitivity of the inspiratory triggering and expiratory cycling systems) influence the "dependent "variables (that is, the tidal volume, respiratory timing and frequency). The setting of the ventilator

\section{() Biomed Central}


during noninvasive PSV is often complicated since the altered respiratory mechanics of COPD patients (that is, the elevated resistances and compliance and intrinsic positive end-expiratory pressure (PEEPi)), together with the presence of air leaks, may deeply interfere with the synchrony between the machine and the patient [7-9]. In intubated patients, a patient/ventilator mismatching is associated with a poor outcome, and during NIV it might determine a bad tolerance to NIV and consequently its failure [10].

The close observation of the ventilator graphics (that is, the flow and pressure waveforms) can be used to detect a gross patient/ventilator mismatching and indirectly, when the flow does not reach zero at the end of expiration, to suppose the presence of PEEPi [11]. It has been suggested, but never directly assessed, that the systematic use of ventilator signals on the screen may be useful in depicting these asynchronies and at the same time in driving the operator in his/her decision to change the settings [11].

The purpose of this randomized controlled study was to compare, in patients under NIV for acute exacerbation of COPD, the efficacy of ventilator settings driven by the analysis of flow and pressure waveforms on the screen (optimized ventilation) vs. a standard ventilation, where only numerical data were obtained from the ventilator. The primary aim was the normalization of $\mathrm{pH}$ (that is, $\geq 7.35$ ) at two hours while secondary aims were the changes in some physiological variables, and the final outcome at 30 days (that is, NIV success rate $v s$. need for endotracheal intubation or death).

\section{Materials and methods Patients and setting}

This multicentric, randomized, prospective, controlled study involved consecutive patients affected by COPD exacerbation (defined as an acute change in a patient's baseline dyspnoea, cough and/or sputum beyond day-today variability sufficient to warrant a change in therapy [12]), and respiratory acidosis (that is, $\mathrm{pH}<7.35$ ) with elevated $\mathrm{PaCO}_{2}(>50 \mathrm{mmHg}$ ) and hypoxemia (that is, $\mathrm{PaO}_{2}<60 \mathrm{mmHg}$ ) that were treated by NIV in addition to standard medical therapy. The study was carried out in five respiratory intermediate intensive care units, where the personnel was well trained in the use of NIV, with at least three years' experience. The study was approved by the local ethical committees and registered at ClinicalTrials.gov with the number NCT01291303. Written informed consent was given by all the patients. The various units all used full-face masks (UltraMirage, ResMed, San Diego, CA, USA; FilLife and PerforMax Respironics, Murryville, PA, USA), and different types of ventilators (Elysée, ResMed-Saime, North Ryde, NSW, Australia; Esprit, Respironics, Murryville PA, USA;
Extend, Taëma, Anthony, France; Servo I, Maquet, Solna, Sweden and Vela, Viasys Healthcare, Palm Springs, CA, USA), all equipped with a screen showing flow and pressure waveforms, and with the opportunity to change both inspiratory and expiratory triggers and initial flow rate. Patients from both groups were ventilated with the same kind of ventilator in every center. Three centers used a heat and moisture exchanger (HME), and two centers used heated humidifiers. Exclusion criteria were the need of intubation or the lack of informed consent. Pre-determined criteria for endotracheal intubation were: 1 ) cardiac and respiratory arrest; 2) worsening of $\mathrm{pH}$ and carbon dioxide tension in arterial blood $\left(\mathrm{PaCO}_{2}\right)$ in spite of NIV administration (for example, $\mathrm{pH}<0.04$ and $\mathrm{PaCO}_{2}>6 \mathrm{mmHg}$ ) [5]; 3) the need to protect the airways; 4) hemodynamic instability (for example, heart rate $<50$ beats/minute with loss of alertness, and/or systolic blood pressure $<70 \mathrm{mmHg}$ ) [5]; and 5) agitation and inability to tolerate the mask [12]. NIV failure was defined as the need for endotracheal intubation or death.

\section{Study protocol}

At the beginning of the trial the patients were randomized using a computer generated sequence [13] to a different ventilator setting:

"Optimized ventilation" (screen analysis-driven ventilation): the operator was allowed to watch the flow and pressure waveforms on the screen in real time and all the changes in the ventilator settings were performed accordingly as specified in details below;

"Standard ventilation": the ventilator screen was obscured with a black paper sheet and only the numerical data were available.

Patients, all treated with maximal medical therapy according to international guidelines [12], were ventilated in PSV mode, with similar initial settings that were: PEEPext of $4 \mathrm{cmH}_{2} \mathrm{O}$ and pressure support (over PEEPext) of $12 \mathrm{~cm} \mathrm{H}_{2} \mathrm{O}$, speed of pressurization as maximum tolerated, inspiratory and expiratory trigger of 5 $\mathrm{L} /$ minute and $50 \%$ of peak inspiratory flow, respectively, and a $\mathrm{FiO}_{2}$ to reach a $\mathrm{SpO}_{2}$ level of about $94 \%$. In order to achieve an adequate level of comfort for the patient at the beginning of the NIV, the attending physician and one nurse spent at least 20 minutes at the bedside.

The general approach (signs of potential patient-ventilator mismatch and action) for the screen analysis driven ventilation (Optimized ventilation) was as follows [8,11,14-18]: 1. Sign: individuation of autotriggering. Action: reduction of air leaks, and/or reduction of inspiratory trigger sensitivity. 2. Sign: individuation of ineffective efforts. Action: titration of pressure support, inspiratory and expiratory triggers, and PEEPext. 3. Signs of potential late cycling-off (pressure increase at 
the end of inspiratory cycle or flow and pressure prolonged plateau). Action: reduction of air leaks and/or titration of expiratory trigger, or setting of maximal inspiratory time. 4. Signs of potential early cycling-off (convex pattern of expiratory flow waveform and concavity of pressure waveform). Action: titration of expiratory trigger. 5. Signs of potentially not balanced PEEPi (expiratory flow that does not reach zero prior to inspiration or ineffective efforts). Action: titration of PEEPext.

As a general rule changes in PS were carried out by steps of $2 \mathrm{cmH}_{2} \mathrm{O}$, and changes in inspiratory and expiratory triggers by steps of 5 to $10 \%$.

\section{Data collection}

The following data were registered for every patient: 1 ) general demographic information; 2) clinical data at baseline and at 30, 120, 360 minutes and 24 hours after the beginning of NIV: blood gas analysis (not at $30 \mathrm{~min}-$ utes), respiratory rate, tidal volume $(\mathrm{Vt})$ expressed per $\mathrm{Kg}$ of ideal body weight (IBW), patients tolerance to ventilation, and ventilator settings (PEEPext, level of pressure support, inspiratory triggering, expiratory cycling, and the speed of pressurization); and 3) the final outcome of the treatment at 30 days (NIV success rate, need for endotracheal intubation, death). The patients' tolerance to ventilation was evaluated with an ad hoc scale, previously validated for five scores: 1) bad; 2) poor; 3) sufficient; 4) good; and 5) very good [19,20]. The patients were asked by the physician to answer the following question: "How do you feel your breathing is at this moment?" For each condition tested, the patient placed a finger on the number that best represented the intensity of their dyspnoea. Moreover, difficulty in inspiration and expiration was evaluated by means of a visual analogue scale (VAS), with a score ranging between 0 and 10 (10 being the highest inspiratory or expiratory difficulty).

\section{Statistical analysis}

The analyzed data were recorded for all 70 patients, with the exception of patients' alarm activations (data available for 40 patients) and the numbers regarding inspiratory triggering (data from 50 patients), since the ventilators used for the remaining patients were equipped with a qualitative scale for setting the inspiratory trigger (ranging from 1 to 5) instead of the absolute value ( $\mathrm{L} /$ minute). According to the number of enrolled patients, a Kolmogorov-Smirnov test was performed before the data analysis in order to examine the data distribution of the overall sample. Normally distributed continuous variables were analyzed with a parametric test (Student's $t$-test), otherwise a nonparametric test (Wilcoxon-Mann-Whitney test) was used; Fisher's test served for categorical data. All data are reported as mean \pm standard deviation (SD), if not otherwise stated. The present study was powered to detect an improvement (increase of success rate) of $\mathrm{pH}$ normalization (that is, $\geq 7.35$ ) at two hours of $40 \%$. To reach a power of $80 \%$ and a significance level of 0.05 in a two-sided test, the number of patients to be enrolled resulted in 35 for each treatment arm. $P$-values $<.05$ were considered statistically significant. Data were analyzed using the Statistical Package for the Social Sciences (version 17.0; SPSS, Chicago, IL, USA).

\section{Results}

The baseline features of the two groups were similar (Table 1).

\section{Primary end point}

"Optimized ventilation" when compared to "standard ventilation" was associated with a higher rate of $\mathrm{pH}$ normalization at two hours (51\% vs. 26\%; $P=0.049$; Figure 1a). After that time frame, this rate, even if always higher in the "optimized ventilation", was not statistically different. Figure $1 \mathrm{~b}$ shows changes in $\mathrm{pH}$ values. While absolute values were not significantly different among groups, patients treated in "optimized ventilation" showed a faster $\mathrm{pH}$ normalization, with a delta $\mathrm{pH}$ (actual data minus baseline values) significantly higher at two and six hours $(P=0.036$ and 0.039 , respectively) when compared with "standard ventilation".

\section{Secondary endpoints}

NIV success rate was similar in the two groups $(86 \%$ and $80 \%$ for "optimized ventilation" and "standard

Table 1 Baseline characteristics of enrolled patients

\begin{tabular}{|c|c|c|c|}
\hline & $\begin{array}{l}\text { Optimized } \\
\text { Ventilation }\end{array}$ & $\begin{array}{c}\text { Standard } \\
\text { ventilation }\end{array}$ & $P$ \\
\hline $\mathrm{N}^{0}$ & 35 & 35 & \\
\hline Age, yrs & $76 \pm 10$ & $79 \pm 7$ & .173 \\
\hline Men, n (\%) & $24(69)$ & $21(60)$ & .618 \\
\hline $\mathrm{BMI}, \mathrm{Kg} / \mathrm{m}^{2}$ & $25.5 \pm 6.2$ & $27.0 \pm 6.3$ & .302 \\
\hline $\mathrm{BMI}>30, \mathrm{n}(\%)$ & $7(20)$ & $8(23)$ & .771 \\
\hline LTOT, n (\%) & $25(71)$ & $20(57)$ & .318 \\
\hline $\begin{array}{l}\text { Domiciliary NIV, } n^{\circ} \\
(\%)\end{array}$ & $3(9)$ & $7(20)$ & .306 \\
\hline \multicolumn{4}{|l|}{ Pre-NIV data } \\
\hline Respiratory rate & $35 \pm 6$ & $33 \pm 7$ & .093 \\
\hline $\mathrm{pH}$ & $7.27 \pm .05$ & $7.28 \pm .05$ & .450 \\
\hline $\mathrm{PaO}_{2} / \mathrm{FiO}_{2}$ & $222 \pm 87$ & $226 \pm 56$ & .796 \\
\hline $\mathrm{PaCO}_{2}, \mathrm{mmHg}$ & $76 \pm 17$ & $71 \pm 12$ & .141 \\
\hline $\mathrm{HCO}_{3}^{-}, \mathrm{mmol} / \mathrm{l}$ & $33 \pm 6$ & $32 \pm 7$ & .569 \\
\hline
\end{tabular}

Data reported as mean \pm standard deviation. No significant differences between groups. BMI, body mass index; LTOT, long-term oxygen therapy; NIV, noninvasive ventilation. 


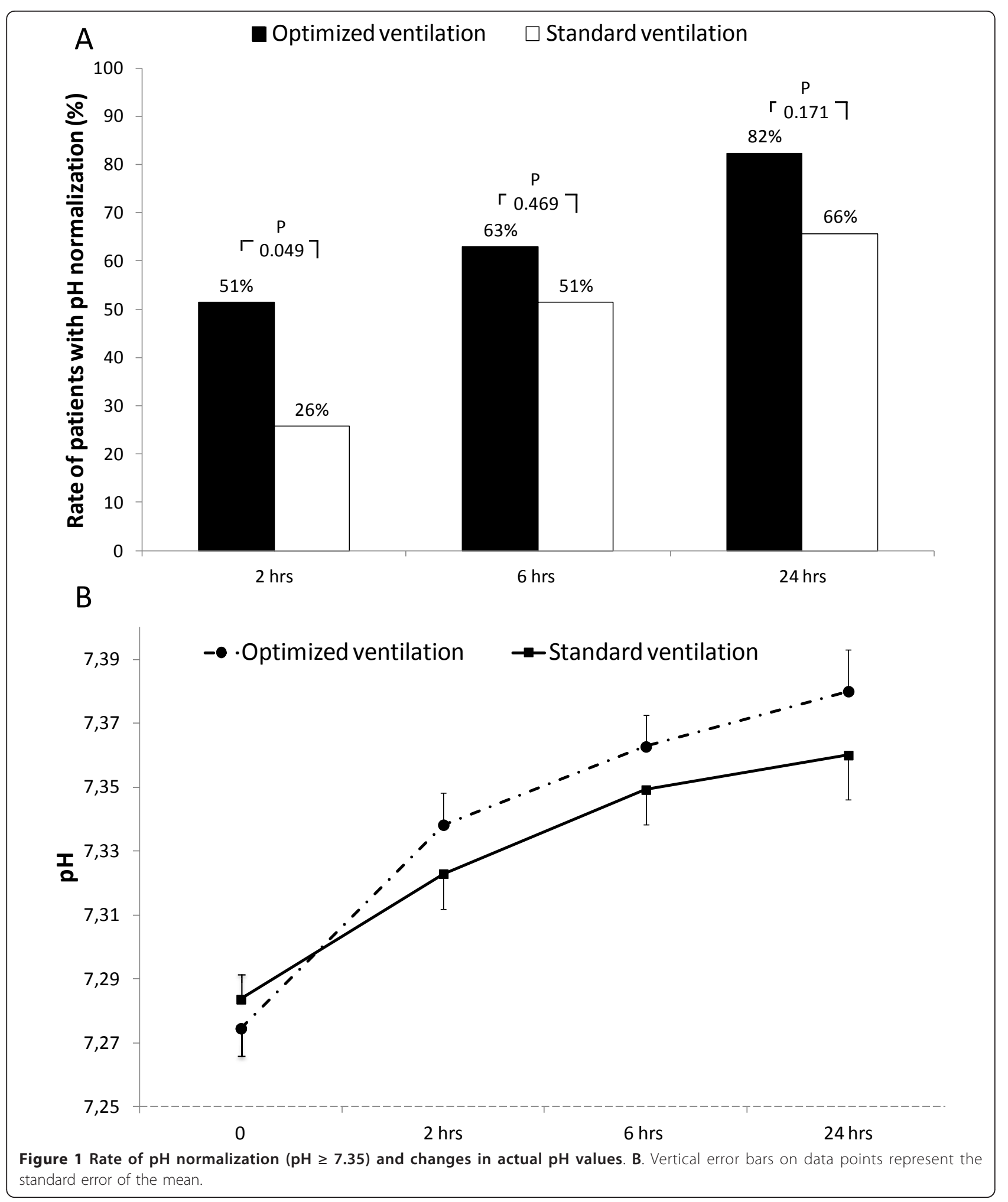

ventilation", respectively, $P=0.752$ ) as well as the overall survival rate at 30 days $(91 \%$ and $89 \%$ for "optimized ventilation" and "standard ventilation", respectively, $P=$ 1.0).
As shown in Figure 2, $\mathrm{PaCO}_{2}$ decreased significantly faster until Hour 6 in the "optimized ventilation", while changes in respiratory rate and tidal volume were similar in both groups (Table 2). 


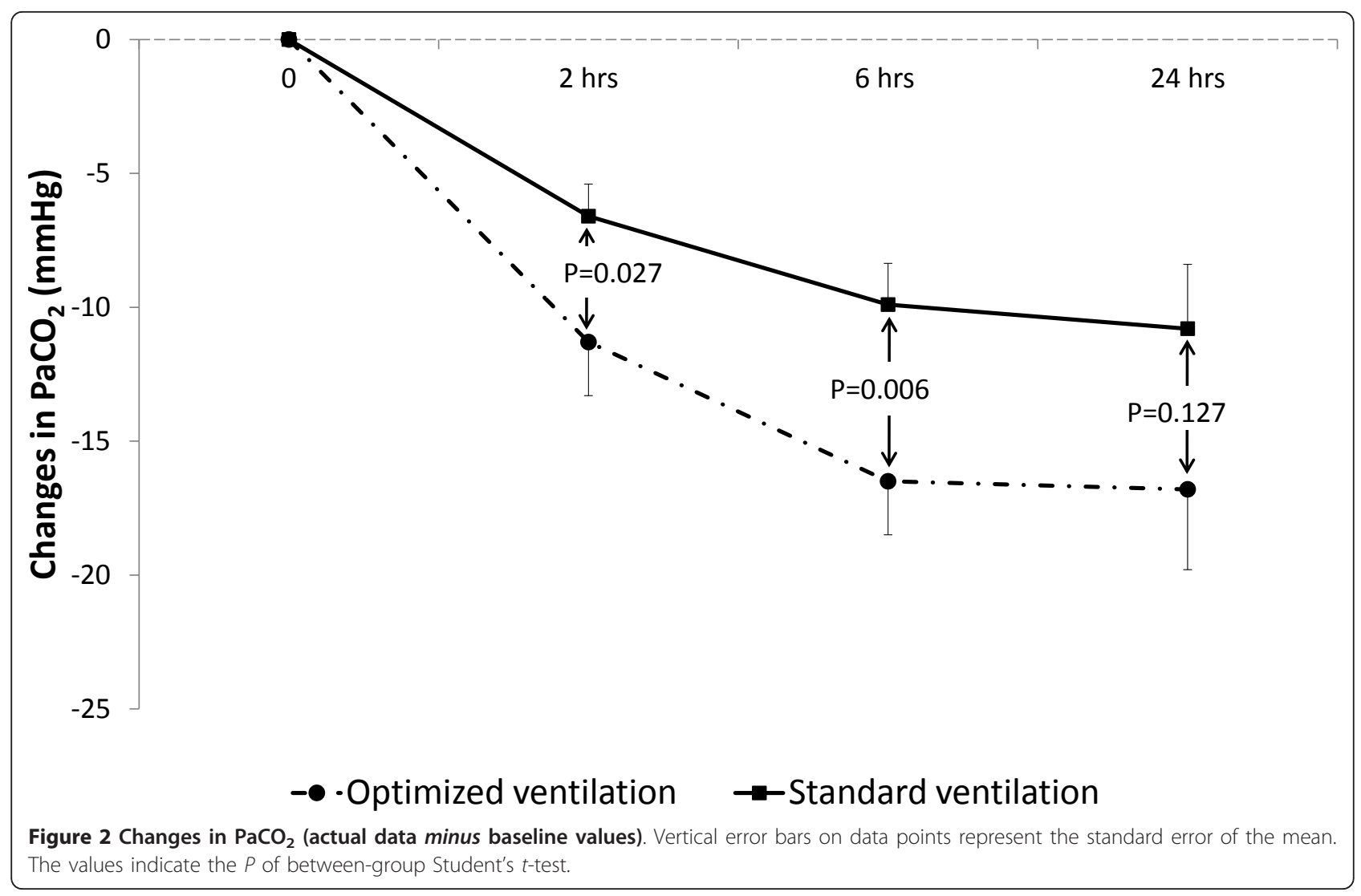

The application of NIV reduced inspiratory and expiratory difficulties in both groups; patients in the "optimized ventilation" group, however, reported a significantly higher tolerance to ventilation at two hours, and less frequently activated the alarm at two and six hours (Table 3).

At all time points patients treated with the "optimized ventilation" settings were ventilated with a higher level

Table 2 Changes of gas exchanges, and respiratory rate during NIV according to treatment

\begin{tabular}{|c|c|c|c|}
\hline & Optimized Ventilation & Standard ventilation & $P$ \\
\hline \multicolumn{4}{|l|}{ After 30 minutes of NIV } \\
\hline RR, cycles/minute & $28 \pm 6$ & $26 \pm 7$ & .197 \\
\hline $\mathrm{Vt} / \mathrm{BW}, \mathrm{ml} / \mathrm{Kg}$ & $7.8 \pm 1.4$ & $7.4 \pm 1.8$ & .316 \\
\hline \multicolumn{4}{|l|}{ After 2 hours of NIV } \\
\hline RR, cycles/minute & $25 \pm 4$ & $24 \pm 6$ & .285 \\
\hline $\mathrm{Vt} / \mathrm{BW}, \mathrm{ml} / \mathrm{Kg}$ & $8.0 \pm 1.7$ & $7.4 \pm 1.8$ & .260 \\
\hline $\mathrm{PaO}_{2} / \mathrm{FiO}_{2}$ & $220 \pm 58$ & $241 \pm 49$ & .119 \\
\hline $\mathrm{HCO}_{3}{ }^{-}, \mathrm{mmol} / \mathrm{l}$ & $33 \pm 6$ & $32 \pm 7$ & .537 \\
\hline \multicolumn{4}{|l|}{ After 6 hours of NIV } \\
\hline RR, cycles/minute & $24 \pm 4$ & $24 \pm 7$ & .827 \\
\hline $\mathrm{Vt} / \mathrm{IBW}, \mathrm{ml} / \mathrm{Kg}$ & $8.0 \pm 2.1$ & $7.6 \pm 2.1$ & .395 \\
\hline $\mathrm{PaO}_{2} / \mathrm{FiO}_{2}$ & $235 \pm 60$ & $243 \pm 37$ & .506 \\
\hline $\mathrm{HCO}_{3}, \mathrm{mmol} / \mathrm{l}$ & $33 \pm 6$ & $32 \pm 7$ & .534 \\
\hline \multicolumn{4}{|l|}{ After 24 hours of NIV } \\
\hline RR, cycles/minute & $22 \pm 6$ & $22 \pm 4$ & .932 \\
\hline $\mathrm{Vt} / \mathrm{IBW}, \mathrm{ml} / \mathrm{Kg}$ & $8.1 \pm 2.4$ & $7.7 \pm 2.1$ & .545 \\
\hline $\mathrm{PaO}_{2} / \mathrm{FiO}_{2}$ & $235 \pm 60$ & $243 \pm 37$ & .713 \\
\hline $\mathrm{HCO}_{3}{ }^{-}, \mathrm{mmol} / \mathrm{l}$ & $35 \pm 7$ & $33 \pm 6$ & .404 \\
\hline
\end{tabular}

Data reported as mean \pm standard deviation. IBW, ideal body weight; RR, respiratory rate; $\mathrm{Vt}$, tidal volume. 
Table 3 Changes in patients' tolerance to ventilation

\begin{tabular}{|c|c|c|c|c|}
\hline & All patients & Optimized ventilation & Standard ventilation & $P$ \\
\hline \multicolumn{5}{|l|}{ At the beginning of NIV } \\
\hline Tolerance to ventilation & $1.5 \pm .7$ & $1.5 \pm .7$ & $1.5 \pm .6$ & .928 \\
\hline Inspiratory difficulty & $7.2 \pm 1.9$ & $7.2 \pm 2.2$ & $7.2 \pm 1.6$ & 1.000 \\
\hline Expiratory difficulty & $7.2 \pm 2.0$ & $7.1 \pm 1.9$ & $7.3 \pm 2.1$ & .735 \\
\hline \multicolumn{5}{|l|}{ After 30 minutes of NIV } \\
\hline Tolerance to ventilation & $2.6 \pm .9$ & $2.7 \pm .8$ & $2.6 \pm .9$ & .663 \\
\hline Inspiratory difficulty & $5.4 \pm 1.3$ & $5.2 \pm 2.2$ & $5.6 \pm 2.0$ & .555 \\
\hline Expiratory difficulty & $5.6 \pm 2.0$ & $5.3 \pm 2.1$ & $5.9 \pm 1.8$ & .304 \\
\hline Pts Alarm activation*, $\mathrm{n}$ & $2.2 \pm 3.1$ & $1.9 \pm 1.7$ & $2.5 \pm 1.9$ & .416 \\
\hline \multicolumn{5}{|l|}{ After 2 hours of NIV } \\
\hline Tolerance to ventilation & $2.3 \pm 8$ & $2.6 \pm .7$ & $1.9 \pm .9$ & .001 \\
\hline Inspiratory difficulty & $4.9 \pm 1.9$ & $4.7 \pm 1.9$ & $5.0 \pm 1.9$ & .494 \\
\hline Expiratory difficulty & $4.8 \pm 2.0$ & $4.8 \pm 2.0$ & $4.9 \pm 2.0$ & .875 \\
\hline Pts Alarm activation*, $\mathrm{n}$ & $1.9 \pm 2.8$ & $1.0 \pm 1.9$ & $3.3 \pm 3.2$ & .004 \\
\hline \multicolumn{5}{|l|}{ After 6 hours of NIV } \\
\hline Tolerance to ventilation & $3.5 \pm .8$ & $3.7 \pm .7$ & $3.3 \pm .9$ & .092 \\
\hline Inspiratory difficulty & $4.0 \pm 2.1$ & $3.7 \pm 2.1$ & $4.2 \pm 2.2$ & .442 \\
\hline Expiratory difficulty & $3.9 \pm 2.1$ & $3.5 \pm 2.0$ & $4.4 \pm 2.2$ & .124 \\
\hline Pts Alarm activation*, $\mathrm{n}$ & $2.3 \pm 2.8$ & $1.1 \pm 1.8$ & $3.4 \pm 3.2$ & .015 \\
\hline \multicolumn{5}{|l|}{ After 24 hours of NIV } \\
\hline Tolerance to ventilation & $3.8 \pm 1.0$ & $3.8 \pm 1.0$ & $3.8 \pm 1.0$ & .921 \\
\hline Inspiratory difficulty & $3.1 \pm 2.1$ & $3.0 \pm 2.2$ & $3.2 \pm 2.1$ & .791 \\
\hline Expiratory difficulty & $3.2 \pm 2.3$ & $3.1 \pm 2.5$ & $3.4 \pm 2.1$ & .657 \\
\hline Pts Alarm activation*, n & $2.3 \pm 3.0$ & $1.1 \pm 1.8$ & $3.4 \pm 3.2$ & .387 \\
\hline
\end{tabular}

Data reported as mean \pm standard deviation. Pts, patients. *Data available in 40 patients. Significant differences in bold.

of PEEPext $(P<0.01$ in all comparisons, see Table 4$)$, without differences for the level of pressure support. Moreover, patients in "optimized ventilation" were ventilated with a more sensitive inspiratory trigger (at all time points, except for the beginning of NIV), and with a faster speed of pressurization until Hour 2 (Table 4).

\section{Discussion}

Our study demonstrated that the real time analysis of pressure and flow waveforms during NIV (optimized ventilation) was associated with a different ventilator setting (that is, higher level of PEEPext, more sensitive inspiratory triggering and faster speed of pressurization) compared to the standard ventilation, leading to a more rapid $\mathrm{pH}$ normalization in patients needing NIV for COPD exacerbation, with a faster $\mathrm{PaCO}_{2}$ reduction in the first six hours of ventilation. Even if the NIV success rate was not affected by this ventilatory approach, these results appear to be of some clinical relevance, since it was previously well demonstrated that the outcome of NIV in patients with acute exacerbation of COPD depends mainly on the early response to the treatment rather than to the baseline severity of the respiratory failure [5].

The baseline severity of the enrolled patients $(\mathrm{pH}$ approximately 7.28 ) reflects the results of a larger clinical trial [5], with minor interference due to the study on the "normal clinical practice" (doctors used the same setting, for example, ventilator, interface and parameter of ventilation usually used in their units), with the only difference due to the obscured screen in the "standard ventilation" group, suggesting a significant external validity of the present study. Moreover, this study was not tailored to detect a difference in terms of NIV success, condition needing a larger sample size.

It is currently accepted that staff training and equipment are two important factors affecting NIV success [21], and that the mechanisms leading to this result can be numerous; our study suggests that one of these may be the interaction between the personnel skills and technology (the possibility of waveforms analysis). In spite of the recent technological advances, both in the algorithm, monitoring and in the overall performances of the new NIV designed ventilators, the experience and the training of the NIV team remain fundamental to understand and judge the behavior of a patient undergoing a supported breathing trial.

Despite several papers that have suggested that the real-time observation of some biological signals (that is, flow and pressure) during mechanical ventilation may be useful in real life, this is the first study (to our 
Table 4 Changes in ventilator setup

\begin{tabular}{|c|c|c|c|c|}
\hline & All patients & Optimized ventilation & Standard ventilation & $P$ \\
\hline \multicolumn{5}{|l|}{ At the beginning of NIV } \\
\hline PEEP, $\mathrm{cmH}_{2} \mathrm{O}$ & $5.1 \pm 1.4$ & $5.5 \pm 1.7$ & $4.7 \pm .9$ & .003 \\
\hline $\mathrm{PS}, \mathrm{CmH}_{2} \mathrm{O}$ & $13.6 \pm 3.4$ & $14.0 \pm 3.7$ & $13.2 \pm 3.1$ & .152 \\
\hline Insp trigger*, L/minute & $3.2 \pm 2.0$ & $2.3 \pm 1.8$ & $4.0 \pm 1.7$ & .002 \\
\hline Expiratory trigger, \% & $40 \pm 9$ & $38 \pm 9$ & $42 \pm 8$ & .086 \\
\hline Speed of pressurization & $1.8 \pm .6$ & $1.7 \pm .6$ & $2.0 \pm .4$ & .024 \\
\hline \multicolumn{5}{|l|}{ After 30 minutes of NIV } \\
\hline PEEP, $\mathrm{cmH}_{2} \mathrm{O}$ & $5.4 \pm 1.3$ & $5.9 \pm 1.4$ & $4.9 \pm .9$ & .011 \\
\hline $\mathrm{PS}, \mathrm{cmH}_{2} \mathrm{O}$ & $14.3 \pm 3.5$ & $14.7 \pm 3.7$ & $14.0 \pm 3.4$ & .604 \\
\hline Insp trigger*, L/minute & $2.9 \pm 2.0$ & $2.0 \pm 1.7$ & $3.8 \pm 1.8$ & .001 \\
\hline Expiratory trigger, \% & $40 \pm 12$ & $40 \pm 14$ & $40 \pm 9$ & .600 \\
\hline Speed of pressurization & $1.6 \pm .5$ & $1.4 \pm .5$ & $1.7 \pm .4$ & .011 \\
\hline \multicolumn{5}{|l|}{ After 2 hours of NIV } \\
\hline PEEP, $\mathrm{cmH}_{2} \mathrm{O}$ & $5.4 \pm 1.2$ & $5.9 \pm 1.3$ & $4.9 \pm .9$ & .030 \\
\hline $\mathrm{PS}, \mathrm{CmH}_{2} \mathrm{O}$ & $14.8 \pm 3.9$ & $14.9 \pm 4.2$ & $14.7 \pm 3.7$ & .820 \\
\hline Insp trigger*, L/minute & $2.9 \pm 2.0$ & $1.9 \pm 1.7$ & $4.1 \pm 1.7$ & 0.001 \\
\hline Expiratory trigger, \% & $37 \pm 12$ & $36 \pm 14$ & $38 \pm 10$ & .337 \\
\hline Speed of pressurization & $1.4 \pm .5$ & $1.3 \pm .5$ & $1.6 \pm .5$ & .064 \\
\hline \multicolumn{5}{|l|}{ After 6 hours of NIV } \\
\hline PEEP, $\mathrm{cmH}_{2} \mathrm{O}$ & $5.4 \pm 1.4$ & $5.8 \pm 1.6$ & $5.1 \pm 1.0$ & .015 \\
\hline $\mathrm{PS}, \mathrm{CmH}_{2} \mathrm{O}$ & $15.3 \pm 4.0$ & $15.5 \pm 4.2$ & $15.1 \pm 4.0$ & .925 \\
\hline Insp trigger*, L/minute & $3.0 \pm 2.0$ & $2.0 \pm 1.7$ & $3.9 \pm 1.8$ & .001 \\
\hline Expiratory trigger, \% & $37 \pm 11$ & $36 \pm 12$ & $39 \pm 10$ & .143 \\
\hline Speed of pressurization & $1.6 \pm .5$ & $1.5 \pm .6$ & $1.7 \pm .5$ & .134 \\
\hline \multicolumn{5}{|l|}{ After 24 hours of NIV } \\
\hline PEEP, $\mathrm{cmH}_{2} \mathrm{O}$ & $5.4 \pm 1.5$ & $6.0 \pm 1.8$ & $4.9 \pm .9$ & .002 \\
\hline $\mathrm{PS}, \mathrm{cmH}_{2} \mathrm{O}$ & $14.8 \pm 3.9$ & $15.4 \pm 4.2$ & $14.3 \pm 3.6$ & .426 \\
\hline Insp trigger*, L/minute & $3.1 \pm 1.9$ & $2.4 \pm 1.8$ & $4.0 \pm 1.8$ & .009 \\
\hline Expiratory trigger, \% & $37 \pm 11$ & $37 \pm 12$ & $37 \pm 10$ & .708 \\
\hline Speed of pressurization & $1.7 \pm .6$ & $1.5 \pm .5$ & $1.9 \pm .6$ & .089 \\
\hline
\end{tabular}

Data reported as mean \pm standard deviation. Insp trigger, inspiratory trigger; PEEP, external positive end expiratory pressure; PS, pressure support (over PEEP). Speed of pressurization: data are reported in a qualitative scale ranging from 0 (faster pressurization) to 5 (slower pressurization). ${ }^{*}$ Data available in 50 patients. Significant differences in bold.

knowledge) showing a potential clinical effect of the socalled screen analysis ventilation.

The mechanisms by which "optimized ventilation" leads to an faster $\mathrm{pH}$ normalization in exacerbated COPD patients treated with NIV can be only speculative, since we did not record the effects of changing the ventilatory settings on ventilation/perfusion ratio, dead space or the mechanical properties of the lungs, using, for example, sophisticated measurements such as the balloon-catheter technique to get values of esophageal and gastric pressures, or the electromyogram of the diaphragm. We hypothesize, that the observed $\mathrm{PaCO}_{2}$ changes are due to differences in the rate between $\mathrm{CO}_{2}$ production and alveolar ventilation. The higher PEEPext in the "optimized ventilation" group can lead to less work in breathing and higher tidal volumes (and probably higher alveolar ventilation). Although the tidal volumes were higher with "optimized ventilation" than with "standard ventilation" (along with stable respiratory frequencies), this difference was not statistically significant. Moreover, we are not able to demonstrate a clear increase in alveolar ventilation with the former method, since we did not measure dead space ventilation. We found significant differences in terms of ventilator settings between the screen driven and standard setting ventilation, with a mild but statistically significant higher PEEPext, a more sensitive inspiratory trigger and faster speed of pressurization in the former group. The difference recorded in terms of PEEPext was related to the changes performed by the clinicians and based on the flow profile, not reaching the zero point at the end of expiration. As a matter of fact the setting of the expiratory pressure is one of the major challenges in the ventilation practice, especially during the exacerbation of COPD where a low PEEPext compared to the measured level of PEEPi may be associated with the elevated work 
of breathing, while on the other side a higher PEEPext could worsen the hyperinflation. Another evocated mechanism for a better, early NIV response could be the optimization of inspiratory and expiratory triggers and pressurization level, to improve patient-ventilator interaction and reduce the work of breathing [11], especially in patients with COPD exacerbation [22]. A better tolerance and adaptation of patients in the "optimized ventilation" group may have decreased the $\mathrm{CO}_{2}$ production and, hence, decreased $\mathrm{PaCO}_{2}$ and increased $\mathrm{pH}$. A better patient-ventilator interaction was indirectly confirmed by a better tolerance of ventilation at two hours and a reduced number of patient alarm activation with "optimized ventilation". Thus, we may corroborate the hypothesis that most of the ventilator-patient asynchronies are likely to be detected by an expert evaluation of pressure and flow waveforms without the need for monitoring the diaphragmatic activity during NIV [16]. Accordingly, an important take-home message in the era of the tremendous spreading of NIV in every setting is that this technique should be applied by a team with great experience in technological skills, such as the capability of analyzing the waveforms generated by the ventilator.

A number of potential limits of the present study deserve discussion. First, we did not evaluate the patients' work of breathing and asynchrony; so we cannot prove that "optimized ventilation" reduces the work of breathing by an improvement of patient-ventilator interaction. The lack of these data might limit generalization of our results, especially to less experienced ICUs. However, our study, due to the lack of invasive methods or a complex study protocol, better reflects the "real clinical practice", significantly increasing the external validity of the results, as previously stated. Second, this study was not double-blinded. Even if the initial setting was pre-defined, we cannot totally rule out a potential bias in the way ventilation was set and managed by the investigators or attending physicians depending on the randomization arm. Moreover, data about patients' scores of encephalopathy and the impact of the "curve-driven" titration of NIV on the time-expenditure of nurses compared to the conventional setting of the ventilator are not available. Finally, as shown in Table 1, the rate of domiciliary NIV in the "standard ventilation" group was double when compared with the "optimized ventilation" group, even if this difference was not statistically significant $(P=0.306)$. This could have theoretically affected the results of the present study. However, a post-hoc subgroup analysis, aimed to compare the results of patients with and without domiciliary NIV, did not find any significant difference.

\section{Conclusions}

The present study demonstrated that "optimized ventilation", driven by the analysis of the waveforms generated by ventilators, may have a positive effect on physiological and patient-centered outcomes during acute exacerbation of COPD. The acquisition of specific skills in this field should be encouraged.

\section{Key messages}

- The setting of the ventilator during noninvasive pressure support ventilation for COPD patients is often intricate, since the altered respiratory mechanics, together with the presence of airleaks, may deeply interfere with the synchrony between the machine and the patient. During NIV, patient-ventilator mismatching might determine a bad tolerance to NIV and, consequently, its failure.

- The close observation of the ventilator graphics (that is, flow and pressure waveforms) can be used to detect a gross patient-ventilator mismatching, and it has been suggested, but never directly assessed, that the systematic use of ventilator signals on the screen may be useful in depicting these asynchronies and at the same time in driving the operator in his/ her decision to change the settings.

- We compared, in patients under NIV for acute exacerbation of COPD, the efficacy of ventilator settings driven by the analysis of flow and pressure waveforms on the screen $v s$. a standard ventilation, where only numerical data were obtained from the ventilator.

- The analysis of flow and pressure waveforms on the screen led to a more rapid normalization of $\mathrm{pH}$ (that is, $\geq 7.35$ ) at two hours (51 vs. $26 \%$ of patients), to a significant improvement of patient's tolerance to ventilation at two hours, and to a higher decrease of $\mathrm{PaCO}_{2}$ at two and six hours. Moreover, the analysis of flow and pressure waveforms on the screen induced physicians to use higher levels of external positive end-expiratory pressure, more sensitive inspiratory triggers and a faster speed of pressurization.

- This is the first study showing a potential clinical effect of screen analysis ventilation. NIV should be applied by a team with a great deal of experience in technological skills, such as the capability of analyzing the waveforms generated by ventilator.

\section{Abbreviations}

COPD: chronic obstructive pulmonary disease; HME: heat and moisture exchanger; IBW: ideal body weight; NIV: noninvasive positive pressure ventilation; PEEPext: external positive end-expiratory pressure; PEEPi: intrinsic positive end-expiratory pressure; PSV: pressure support ventilation; SD: standard deviation; VAS: visual analogue scale; Vt: tidal volume. 


\section{Author details}

${ }^{1}$ Pneumologia Ospedale San Paolo, Università degli Studi di Milano, via A. di Rudinì 8, Milano, 20142, Italy. ${ }^{2}$ Emergency Department, Valduce Hospital, via Dante Alighieri 11, Como, 22100, Italy. ${ }^{3}$ U. O. Clinica Pneumologica, Università degli Studi di Milano-Bicocca, Azienda Ospedaliera S. Gerardo, via Pergolesi 33, Monza, 20900, Italy. ${ }^{4}$ Pneumologia e UTSIR, Ospedale Campo di Marte, via dell'Ospedale 1, Lucca, 55100, Italy. ${ }^{5}$ ICU, Ospedale Regionale Bellinzona e Valli, viale Officina 3, Bellinzona 6500, Switzerland. ${ }^{6}$ Respiratory and Critical Care Unit, Sant'Orsola Malpighi Hospital, via Albertoni 15, Bologna, 40138, Italy.

\section{Authors' contributions}

SN conceived the study. FDM conceived the study, was responsible for data collection in his center, performed statistical analysis and drafted the manuscript. All authors participated in the study design, were responsible for data collection in their centers, and read and approved the final manuscript for publication.

\section{Competing interests}

The authors declare that they have no competing interests.

Received: 26 August 2011 Revised: 21 October 2011

Accepted: 24 November 2011 Published: 24 November 2011

\section{References}

1. Brochard L, Mancebo J, Wysocki M, Lofaso F, Conti G, Rauss A, Simonneau G, Benito S, Gasparetto A, Lemaire F, Isabey D, Harf A: Noninvasive ventilation for acute exacerbations of chronic obstructive pulmonary disease. N Engl J Med 1995, 333:817-822.

2. Lightowler JV, Wedzicha JA, Elliott MW, Ram FS: Non-invasive positive pressure ventilation to treat respiratory failure resulting from exacerbations of chronic obstructive pulmonary disease: Cochrane systematic review and meta-analysis. BMJ 2003, 326:185.

3. Nava S, Hill N: Non-invasive ventilation in acute respiratory failure. Lancet 2009, 374:250-259

4. Bott J, Carroll MP, Conway JH, Keilty SE, Ward EM, Brown AM, Paul EA, Elliott MW, Godfrey RC, Wedzicha JA: Randomised controlled trial of nasal ventilation in acute ventilatory failure due to chronic obstructive airways disease. Lancet 1993, 341:1555-1557.

5. Confalonieri M, Garuti G, Cattaruzza MS, Osborn JF, Antonelli M, Conti G, Kodric M, Resta O, Marchese S, Gregoretti C, Rossi A: A chart of failure risk for noninvasive ventilation in patients with COPD exacerbation. Eur Respir J 2005, 25:348-355.

6. Kramer N, Meyer TJ, Meharg J, Cece RD, Hill NS: Randomized, prospective trial of noninvasive positive pressure ventilation in acute respiratory failure. Am J Respir Crit Care Med 1995, 151:1799-1806.

7. Thille AW, Rodriguez P, Cabello B, Lellouche F, Brochard L: Patientventilator asynchrony during assisted mechanical ventilation. Intensive Care Med 2006, 32:1515-1522.

8. Jolliet $P$, Tassaux D: Clinical review: patient-ventilator interaction in chronic obstructive pulmonary disease. Crit Care 2006, 10:236.

9. Nava S, Bruschi C, Rubini F, Palo A, lotti G, Braschi A: Respiratory response and inspiratory effort during pressure support ventilation in COPD patients. Intensive Care Med 1995, 21:871-879.

10. Epstein SK: How often does patient-ventilator asynchrony occur and what are the consequences? Respir Care 2011, 56:25-38.

11. Nilsestuen JO, Hargett KD: Using ventilator graphics to identify patientventilator asynchrony. Respir Care 2005, 50:202-234, discussion 232-204.

12. Celli BR, MacNee W: Standards for the diagnosis and treatment of patients with COPD: a summary of the ATS/ERS position paper. Eur Respir J 2004, 23:932-946.

13. Randomization Plan Generator. [http://www.randomization.com]

14. Gladwin MT, Pierson DJ: Mechanical ventilation of the patient with severe chronic obstructive pulmonary disease. Intensive Care Med 1998 24:898-910.

15. Thille AW, Cabello B, Galia F, Lyazidi A, Brochard L: Reduction of patientventilator asynchrony by reducing tidal volume during pressure-support ventilation. Intensive Care Med 2008, 34:1477-1486.

16. Vignaux L, Vargas F, Roeseler J, Tassaux D, Thille AW, Kossowsky MP, Brochard $\mathrm{L}$, Jolliet P: Patient-ventilator asynchrony during non-invasive ventilation for acute respiratory failure: a multicenter study. Intensive Care Med 2009, 35:840-846.

17. Parthasarathy S, Jubran A, Tobin MJ: Cycling of inspiratory and expiratory muscle groups with the ventilator in airflow limitation. Am J Respir Crit Care Med 1998, 158:1471-1478.

18. Prinianakis G, Plataki M, Kondili E, Klimathianaki M, Vaporidi K, Georgopoulos D: Effects of relaxation of inspiratory muscles on ventilator pressure during pressure support. Intensive Care Med 2008, 34:70-74.

19. Nava S, Ambrosino N, Bruschi C, Confalonieri M, Rampulla C: Physiological effects of flow and pressure triggering during non-invasive mechanical ventilation in patients with chronic obstructive pulmonary disease. Thorax 1997, 52:249-254.

20. Vitacca M, Rubini F, Foglio K, Scalvini S, Nava S, Ambrosino N: Non-invasive modalities of positive pressure ventilation improve the outcome of acute exacerbations in COLD patients. Intensive Care Med 1993, 19:450-455.

21. Nava S, Ceriana P: Causes of failure of noninvasive mechanical ventilation. Respir Care 2004, 49:295-303.

22. Tassaux D, Gainnier M, Battisti A, Jolliet P: Impact of expiratory trigger setting on delayed cycling and inspiratory muscle workload. Am J Respir Crit Care Med 2005, 172:1283-1289.

doi:10.1186/cc10567

Cite this article as: Di Marco et al:: Optimization of ventilator setting by flow and pressure waveforms analysis during noninvasive ventilation for acute exacerbations of COPD: a multicentric randomized controlled trial. Critical Care 2011 15:R283.

\section{Submit your next manuscript to BioMed Central and take full advantage of:}

- Convenient online submission

- Thorough peer review

- No space constraints or color figure charges

- Immediate publication on acceptance

- Inclusion in PubMed, CAS, Scopus and Google Scholar

- Research which is freely available for redistribution

Submit your manuscript a www.biomedcentral.com/submit
Ciomed Central 